\title{
PERSEA AMERICANA: DETERMINAÇÃO DE COMPOSTOS FENÓLICOS POR CLAE-DAD.
}

\author{
Cíntia de Souza Silva ${ }^{1}$; Sônia Carine Cova $\operatorname{Costa}^{2}$; Isabella Mary Alves Reis ${ }^{3}$ \\ 1. Bolsista PIBIC/CNPq, Graduanda em Farmácia, Universidade Estadual de Feira de Santana, email: \\ csty8@hotmail.com \\ 2. Orientadora, Departamento de Saúde, Universidade Estadual de Feira de Santana, email: scarinecc@ @otmail.com \\ 3. Doutoranda em Biotecnologia, Departamento de Biologia, Universidade Estadual de Feira de Santana.
}

PALAVRAS-CHAVE: Persea; compostos fenólicos; abacate.

\section{INTRODUÇÃO}

A utilização de espécies vegetais pelo homem para os mais diversos propósitos é uma atividade que se confunde com a própria existência humana. Observa-se que em todas as fases de desenvolvimento das diversas civilizações sempre prevaleceu uma estreita relação entre o homem e as plantas (DAVID; DAVID, 2010). E, dentre as inúmeras espécies vegetais com finalidades terapêuticas destaca-se a Persea americana (abacateiro). Seus frutos são conhecidos como abacates, que possuem a casca verde-oliva e polpa amarela clara que é rica em óleos vegetais (LEITE et al., 2009). O abacate possui notável qualidade nutricional, bem como elevados níveis de compostos fitoquímicos bioativos, incluindo a vitamina $\mathrm{E}$, carotenoides, esteróis, compostos fenólicos, entre outros (DAIUTO et al., 2014).

A avaliação do potencial terapêutico de plantas medicinais e de alguns de seus constituintes, tais como flavonóides, alcalóides, taninos e outros, tem sido objeto de incessantes estudos, onde já foram comprovadas ações farmacológicas (CECHINEL; YUNES, 1998). Desta maneira, o presente trabalho visou buscar a determinação de compostos fenólicos por Cromatografia Líquida de Alta Eficiência com Detector de Arranjo de Diodos (CLAE-DAD) em P. americana.

\section{METODOLOGIA}

A coleta de $1,05 \mathrm{~kg}$ dos frutos de $P$. americana foi realizada na região de Feira de Santana, BA. Os frutos sadios da espécie vegetal foram higienizados, cortados em finas fatias e secos em estufa com temperatura controlada $\left(50^{\circ} \mathrm{C}\right)$. Sendo posteriormente triturado em liquidificador industrial. $\mathrm{O}$ pó resultante $(500 \mathrm{~g})$ foi submetido à maceração em etanol $(\mathrm{EtOH})$ por cerca de cinco dias, em seguida o material foi filtrado. O extrato bruto etanólico foi obtido após concentração do filtrado em rotaevaporador, sendo em aproximadamente 95g.

A análise do extrato etanólico foi realizado em Cromatógrafo Líquido de Alta eficiência (Merck-Hitachi LaChrom Elite ${ }^{\circledR}$ ), equipado com Detector de Arranjo de Diodos (DAD). A fase móvel era composta por um gradiente de $\mathrm{H}_{2} \mathrm{O} / \mathrm{H}_{3} \mathrm{PO}_{4} 0,1 \%$ (A) e $\mathrm{MeOH}(\mathrm{B})$, sendo de 0-37 min A:B (100:0), de 37-42 min A:B (0:100) e de 43-45 min (80:20). O fluxo da fase móvel foi mantido a $1 \mathrm{~mL} / \mathrm{min}$ e a temperatura da coluna a $30^{\circ} \mathrm{C}$. Os espectros no UV foram adquiridos na faixa de 200 a $400 \mathrm{~nm}$, sendo que para registro dos cromatogramas, os comprimentos de onda foram escolhidos após as análises.

\section{RESULTADOS E DISCUSSÃO}

A técnica de análise por CLAE-DAD é a mais apropriada para uma separação mais eficiente de extratos brutos e está entre as mais utilizadas para identificação e quantificação de compostos fenólicos (ASSIS, 2014). O extrato etanólico de P. americana apresentou 
rendimento de $19 \%$ e a partir de sua análise por CLAE-DAD houve a possibilidade obter o perfil dos constituintes químicos presentes no mesmo.

O cromatograma dessa amostra (Figura 1), monitorado em $360 \mathrm{~nm}$, apresentou picos com tempos de retenção entre 15 e 25 minutos, o que indica a presença de substâncias de média polaridade, isso porque, na CLAE em fase reversa, quanto menor a polaridade da substância maior o seu tempo de retenção, devido sua maior afinidade com a coluna, quando comparadas aos compostos com características mais polares. O pico majoritário com Tr. 20, 29 minutos apresentou espectro de UV típico de compostos fenólicos com bandas de absorção no UV em 233 e $342 \mathrm{~nm}$. Os picos minoritários presentes na amostra pertencem a substâncias da mesma classe do composto majoritário, isto porque por apresentam espectros de UV com bandas de absorção semelhantes e assim grupos de cromóforos iguais.

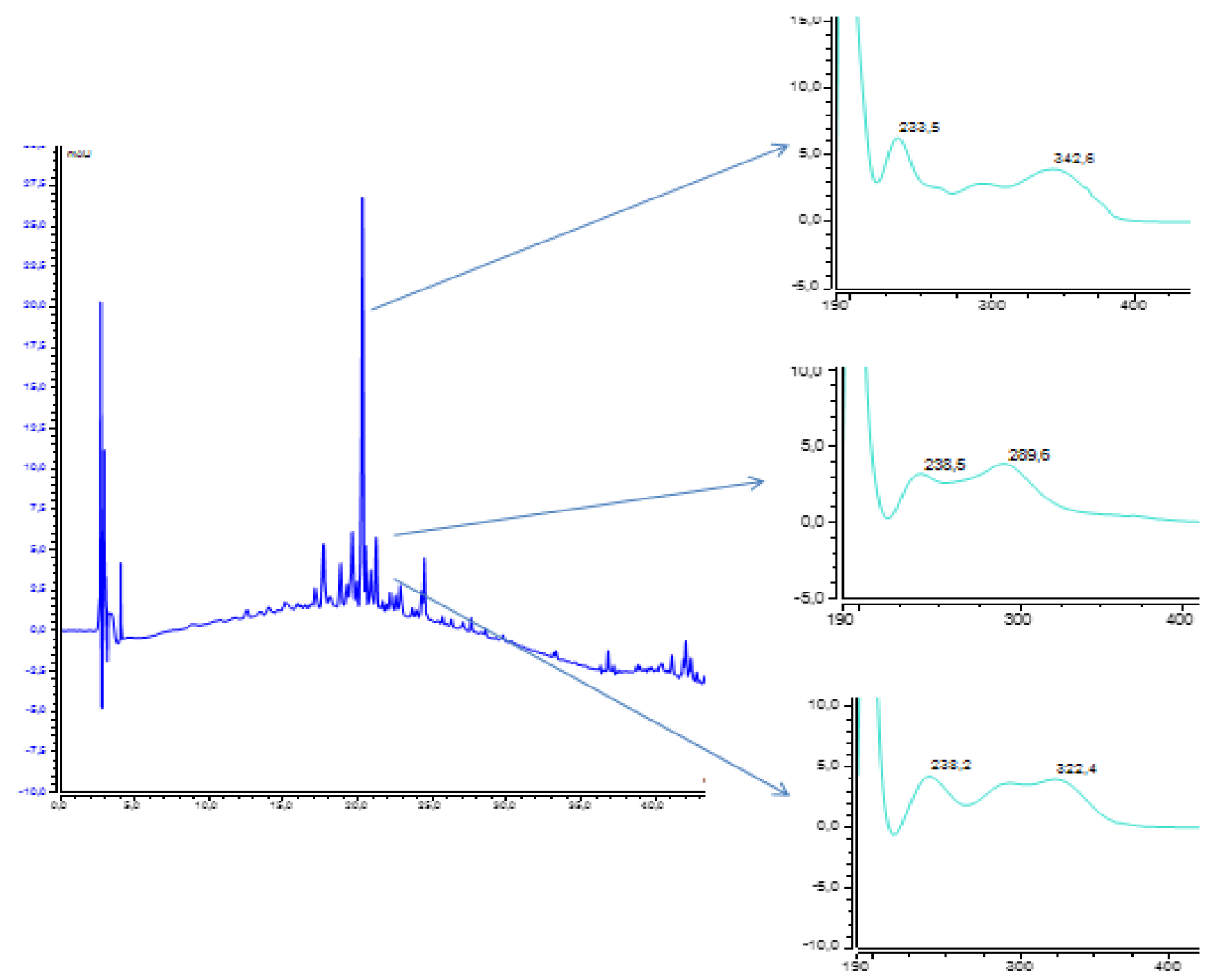

Figura 1. Cromatograma do extrato etanólico de Persea americana.

Segundo Poovarodom et al. (2010) se identificou em amostras de Persea americana compostos como ácido $p$-hidroxibenzoico, vanílico, cafeico e ferúlico, bem como também flavonoides. Ainda de acordo com Torres \& Mau-Lastovicka \& Rezaaiyan (1987) foram detectados 16 ácidos fenólicos, sendo dentre eles o ácido gálico, isovanílico, $p$-cumárico. 


\section{CONCLUSÃO}

A crescente demanda social por produtos que sejam provenientes especialmente de fontes naturais impulsiona o desenvolvimento de pesquisas. Assim, a partir deste estudo demonstrou-se que o perfil de constituintes químicos é de compostos fenólicos, esses que são uma grande classe de compostos fitoquímicos distribuídos principalmente nas frutas, sendo os principais responsáveis pela atividade antioxidante (DAIUTO et al., 2014). Desta forma, há perspectivas futuras tendo em vista novas pesquisas e estudos que culminarão na maior elucidação dos compostos químicos da $P$. americana, bem como seu potencial terapêutico resultando assim na otimização do uso medicinal.

\section{REFERÊNCIAS}

ASSIS, M. L. V. Determinação do potencial antioxidante e quantificação de compostos fenólicos por CLAE em acessos de Capsicum baccatum var. pendulum. 2014. 117f. Dissertação (Mestrado) - Curso de Química, Centro de Ciências e Tecnologias Agropecuárias, Universidade Estadual do Norte Fluminense Darcy Ribeiro, Campos dos Goytacazes, RJ, 2014.

CECHINEL FILHO, V; YUNES, R. A. Estratégias para a obtenção de compostos farmacologicamente ativos a partir de plantas medicinais. Conceitos sobre modificações estrutural para otimização da atividade. Química Nova, v. 21, n. 1, p. 99, 1998.

DAIUTO, E. R. Composição Química e Atividade Antioxidante da Polpa e resíduos de abacate 'Hass'. Revista Brasileira de Fruticultura, Jaboticabal, SP, v.36, n.2, p.417-424, 2014.

DAVID, J. P.; DAVID, J. M. Plantas medicinais, fármacos derivados de plantas. In: SILVA, P. Farmacologia. 8. ed. Rio de Janeiro: Guanabara Koogan, 2010. p. 147-158.

LEITE, J. J. et al. Chemical composition, toxicity and larvicidal and antifungal activities of Persea americana (avocado) seed extracts. Revista Sociedade Brasileira de Medicina Tropical, Uberaba, v.42, n.2, p. 110-113, Mar./abr. 2009.

POOVARODOM, S. et al. Comparative characterisation of durian, mango and avocado. International Journal of Food Science and Technology, v. 45, p. 921-929, 2010.

TORRES, A. M.; TERRY, M.; REZAAIYAN, R. Total phenolics and High- Perfomance Liquid Chromatography of Phenolic Acids of Avocado. J. Agric. Food Chem., v.35, n.6, 1987. 